\title{
HUMAN RESOURCES MANAGEMENT IN HOTEL INDUSTRY: THE ANALYSIS OF CURRENT PRACTICES IN SERBIA
}

Svetozar Krstić

Belgrade Chambre of Commerce Belgrade, Serbia

\begin{abstract}
:
Human resources management (HRM) in the hotel industry, especially in large hotel chains, has rapidly developed in the last few decades, by means of modern HRM assets. Today, a wide range of measures is being used in HRM, aimed at career development, such as systems of vocational trainings, rewarding incentives, and the promotion of healthy working environment, with stress minimization in the workplace. The importance of HRM in the hotel industry is constantly growing. Hotels have an important role to attract, engage and maintain top talents, by redefining working environment and creating stimulating work ambiance. Efficient HR managers also have to be familiar with constantly changing business practices and tendencies. This study presents the comparative analysis of HRM practices in Serbia in 2015, according to the Cranet research, and the HRM practice in the hotel industry, conducted by the author in 2015, encompassing twenty hotels in Serbia. It also comprehends the most important cases of practice in hotel chains worldwide.
\end{abstract}

Keywords:

hotel, HRM, employee, hotel industry.

\section{INTRODUCTION}

One of the most important challenges of hotel chains worldwide is the constant promotion of HRM. The task is challenging not only because of the size and various locations of hotel chains, but also because of different regulations, customs and culture in regions worldwide. Some hotels implement large hotel chains standards and best practices of HRM through franchise agreements and relations. Despite the fact that the relationships with employees are not, in this case, the responsibility of hotel chains franchisors, but of particular hotels, which are in that case franchisees, large hotel chains franchisors often insist on detailed determining of obligations related to good HRM practices. These obligations are related to the employee promotion, permanent training system, rewarding and recruiting system etc. Franchisors provide support through trainings and similar education events that employees attend in franchisors' schools, which counts among the most important forms of support to business development and promotion. ${ }^{1}$

1 Review of socially responsible HR practice and labor relations in international hotel chains, ILO 2008
Correspondence:

e-mail:

krstics@kombeg.org.rs 
The employee structure in the hotel industry is more complex compared to other sectors, since hotels employ not only the staff with definite and indefinite duration of agreements and full-time and part-time employees, but also a large number of seasonal workers, apprentices, contract workers etc. All of them need to do their jobs in a highly professional manner in order to avoid the divergence of standards and quality level, and thus have to be included in the training system. Precisely, the readiness of hotel chains to educate and train entire staff presents the evidence of HRM effectiveness. The fact that IHG group operates in more than 100 countries and manages over 5000 hotels $^{2}$, Marriot in 87 countries managing 4500 hotels $^{3}$, and Hilton in 104 countries with 4700 hotels $^{4}$, illustrates the complexity of good management practices.

The strategic importance of HRM is reflected primarily in understanding and insisting on the importance of people and their potential in the constantly changing world, as well as the acknowledgment of their key contribution in gaining competitive advantages of the hotel. This advantage can only be provided by talented employees and consequently, the most important role and objective of HRM is to attract such employees, develop their potentials and keep them, in order to increase competitiveness and preserve competitive advantages.

HRM is a relatively inexpensive function and does not require large resources for development. It significantly affects the return on investments and enables an increase of added value of business operations in each organization. The role of HRM is to follow and analyze the organization and its jobs, integration in cultural system, goal achievement, as well as to initiate and implement changes and promotions when needed.

Global Talent Trends and Issues for the Travel and Tourism sector, 2015, points out, for the first time, the problem of shortage of talented workers in tourism and travel sector, including the hotel industry. The research has shown that this sector is facing, on the global level, the annual deficit of 14 million jobs. The research has also shown that the sector of travel and tourism faces significant problem of lack of talents, more that in the economy as a whole. This study predicts a lack of talents in 6 out of 46 countries in the next 5 to 10 years (WTTC, 2015, p. 1).

The President and CEO of the World Travel and Tourism Council, Mr. David Scowsill emphasizes: „We are a people industry - we depend on quality people to

2 www.ihg.com

3 www.marriot.com

4 www.hiltonworldwide.com deliver a quality product - and we need the right policies, programs and partnerships in place to ensure that the workforce of the future knows about the opportunities in our sector, and has the appropriate skills and knowledge to support future growth. In the years to come, progress in developing and retaining talent will require a much stronger and more coordinated effort between the private sector, educational establishments and government" (WTTC, 2015, p. 1).

\section{THE CURRENT PRACTICE OF HUMAN RESOURCES}

\section{Importance of human resources in vision, mission and principles of businesses}

International hotel chains transparently publish their visions and missions, in which as a rule they emphasize the importance of the staff and their active role in the achievement of company's goals. In this context, Hilton iScandic refers to their employees as team members, Mandarin Oriental as colleagues, while Marriot, Starwood and Hyatt talk about their associates (Boardman \& Barbato, 2008, p. 22).

Innovative vision of Marriot chain, responsible for the global success of the company, is based on the slogan "Spirit to Serve". They foster the working environment in which employees are truly valued, which results in extraordinary service level and profit increase. In Marriot, success starts with employees, and thus, the employer makes sure they have all necessary tools and trainings to constantly develop. Employee dedication is rewarded with compensations, promotion possibilities and other benefits. Spirit to serve is based on a fixed condition that people are the core value of the company. Employees work in the environment that supports their development, the employer takes good care of the staff, which is in return ethical and trustworthy. Workplace feels like home, working environment is friendly, and the rewarding system recognizes the importance of employees and managing staff 5 .

Employees have the crucial role in defining and achieving the vision, values, missions and principles of hotel chain business operations. For this reason, the leading hotel chains determine a set of policies which present the globalization tool in HRM. These policies concern human rights, equal opportunity and diversity rights, harassment prohibition etc. Most of the hotel chains worldwide determines and brands their own HRM programs, which present tools that accelerate goal achievement both regionally and globally.

$5 \quad$ www.mariot.com 
Shangri-La has created training programs called "Care". All new staff undergo the modules within six months of joining the group. Employees gain the skills needed to "turn passion into a success" 6 .

According to Cranet research (Leković et al., 2015, p. 28) ${ }^{7}$, most of the surveyed organizations possess the written statement on mission, vision and business strategy. Approximately $60 \%$ of companies have formulated the general HR strategy, while half of the surveyed companies have the partial HR strategy.

According to the research conducted by the author, out of 20 surveyed hotels, only three have stated companies' objectives on their websites. They communicate with the community and future guests and clearly affirm that their objective is guest satisfaction. They also commit themselves to providing the highest possible level of services. The rest of hotels (17) do not state their vision and mission on their websites.

Such attitude towards the expression of hotels' mission and vision shows that hotel managers are not aware of the importance of the link between the mission, vision and employees' achievement of objectives. Understanding and accepting the mission and vision by all the employees present one of the key pillars of efficient HRM, since it shows the most important strategic orientations of the hotel and the basis for construction of organizational culture. Visions and missions also articulate core system values that should be promoted by the organization and its members.

According the assessments of twenty hotel managers, the main challenge HRM is facing in hotel industry is related to the methods of recruiting and selecting the appropriate working force (especially middle skilled staff), which is ready to learn and accept innovations in order to provide high level quality services to guests. Other important issues for HRM are the investment in employees, trainings, teamwork fostering, and acknowledgement of the importance of communication, employee motivation, and adequate choice of jobs according to employee skills.

\section{Recruiting}

According to the conclusions of Cranet survey (Leković et al., 2015, p. 28), majority of surveyed organizations prefer intern recruiting for managerial and expert positions, as well as for administrative positions and manual

6 www.shangrila.com

7 Cranet research comprehends 158 organizations, 2/3 from private and $1 / 3$ from public sector. When it comes to sector structure, $1 / 3$ of surveyed organizations belong to manufacturing sector and 2/3 to the service sector. Approximately $60 \%$ of participants belong to SME sector. workers (in more than $50 \%$ cases). The most frequently used methods are recommendations and internet and newspaper ads. The most frequently used method for management recruiting is the Internet (over 30\%). As regards skilled workers, the most popular extern source of recruiting is National Employment Service, followed by internet ads and standing job advertisement. For administrative and manual workers, besides already stated, extern methods, newspapers ads are also frequently used. Public networks, as an innovative recruiting method, are being used only in 10-15\% of hotels, depending on the employee category.

Author's research related to the recruitment practices examined the most frequently used recruiting sources, their utility assessment and effectiveness. Less than a half of respondents have a recruitment plan (43\%). While recruiting, they dominantly cooperate with educational institutions, and the Internet. When assessing the utility of each recruitment source, the respondents consider the Internet the most useful asset (average rank 1.45), followed by other sources (1.75) and the cooperation with educational institutions (1.77). According to the results, advertising in newspapers and professional journals is far less useful (average ranks 3.88 and 4.56, respectively). According to Cranet survey, the most used recruitment methods in Serbia are recommendations and newspaper and internet ads.

Strategies used in recruiting are: the creation of database of candidates (based on experiences with candidates that have accomplished vocational trainings, candidates applied via the Internet and candidates with recommendations), selection of candidates with best results on vocational trainings, and recommendation of colleagues and probation results. Only $38 \%$ of respondents conduct the evaluation of recruitment effectiveness.

\section{Selection}

According to Cranet survey (Leković et al., 2015, p. 28), special attention is paid to individual interviews (this method is used in $60 \%$ of organizations) and recommendations (more than 50\%) in the process of selection of managers and skilled workers. In addition to individual interviews, filling out application forms is also important while selecting administrative staff and manual workers (the method is used in $60 \%$ of organizations). A small share of the observed organizations disposes of special action programs for hiring specific categories of workers. Author's survey conducted in hotel organizations shows that the HRM selection instrument is used in all of the surveyed organizations. There is a high uniformity in types and intensity of used selection methods. 


\section{Utility of recruiting sources expressed through average rank}

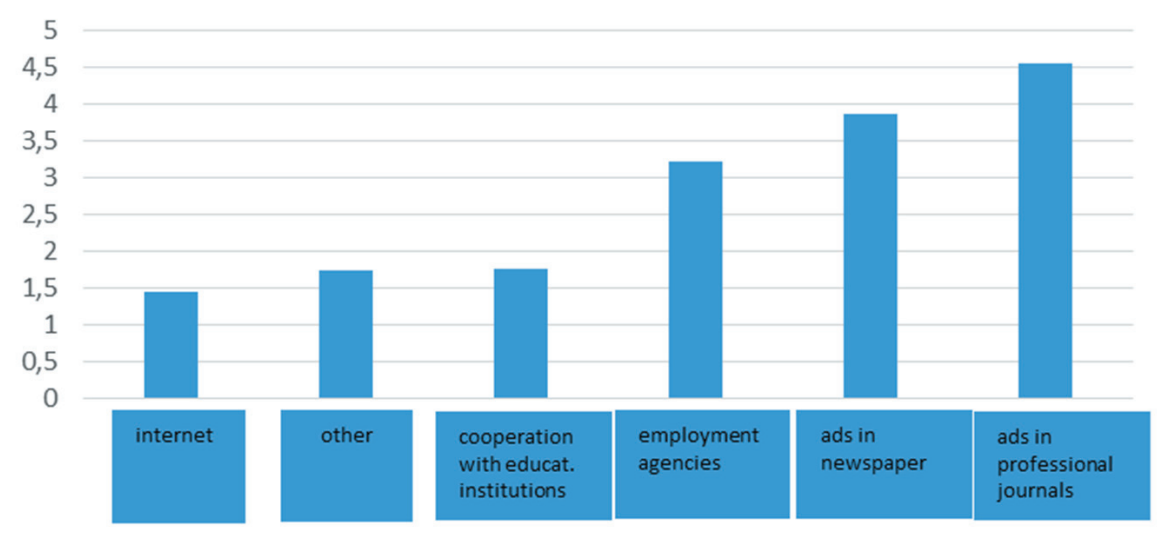

Figure 1. Utility of recruiting sources expressed through the average rank

There are differences within the selection process, while hiring for managerial and executive positions (71\%). These differences refer primarily to the content, and less to the types of methods.

\section{Training and development}

Cranet research shows that when it comes to the employee training, in most of the surveyed organizations, average share of training costs is $2.68 \%$ of total annual training costs, which proves a modest importance of trainings in Serbian companies. In private sector, more important amounts are allocated for employees' trainings (2.86\%), compared to public companies $(2.32 \%$ of total salary costs). In the surveyed public companies, an employee spends six days per year on trainings. In private companies, managers are trained for more than 7 days per year, skilled staff almost 7 days and administrative and manual workers more than 5 days. In public sectors, the greatest attention is given to the education of skilled staff, with nearly 6 paid days of training per year. Managers in public sector spend more than 5 days on different types of trainings, while administrative and manual workers are being trained less than 4 days every year. Besides the number of days spent on trainings, the measurement of training efficiency is an important indicator as well. In most of the organizations, informal feedback is being used. In addition, most of our organizations measure the achievement of goals set in the training plan. More objective methods, such as measurement of participants' performance before, immediately after and a month following the training, or the return of investment are not often used (Leković et al., 2015, p. 29). The research also shows that only half of respondents have elaborated plans for employee trainings. If they have plans, they refer to the acquisition of specialized knowledge related to the hotel industry (2), training programs for middle position employees (1), internal trainings for newly employed staff (1), communication trainings (1); and crisis resolving (1). Even if the trainings are mandatory for all employees, only $43 \%$ of respondents evaluate the acquired knowledge.

\section{SELECTION METHODS}

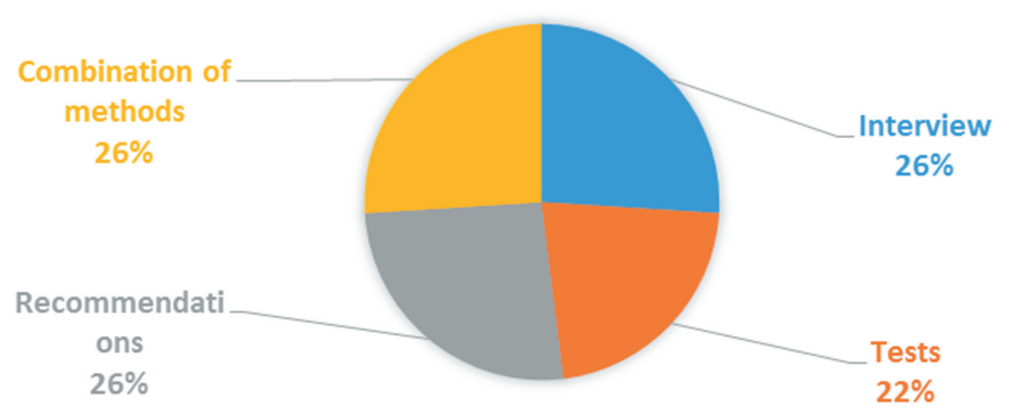

Figure 2. Selection methods 


\section{FLUCTUATION}

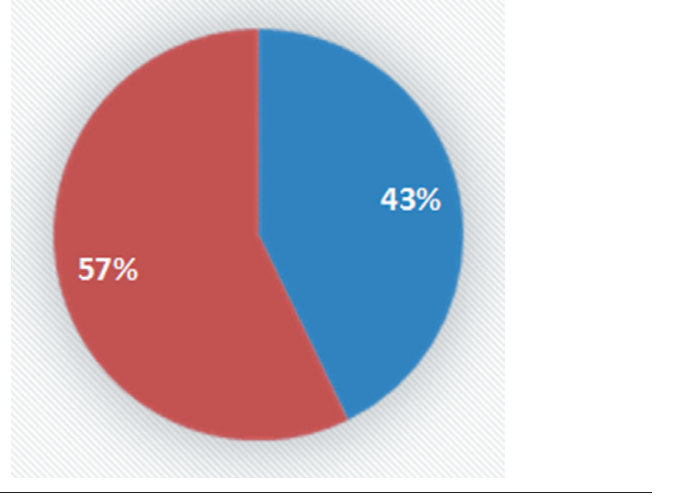

Figure 3. Evaluation of acquired knowledge

\section{EVALUATION}

Cranet research shows that most of the organizations formally evaluate the employee performance. In approximately $80 \%$ of the surveyed organizations from private sector, formal evaluation methods exist for the evaluation of managers, skilled staff and administrative and manual workers. The share is smaller in public sector, where $75 \%$ of skilled workers are being evaluated, while the performance of administrative and manual workers and managers is evaluated only in $60 \%$ of the surveyed organizations. In the majority of surveyed organizations, evaluation of work results is carried out by direct supervisors. Supervisors' superiors are engaged in this process only in $1 / 3$ of surveyed organizations. The appropriate multilateral evaluation exists only one out of five of the surveyed companies, and these cases are related to managerial positions. As regards skilled and administrative/manual staff, subordinates and colleagues provide performance feedback in less than $10 \%$ of cases. In the surveyed organizations, performance results of management system are used as inputs for compensation, training and career development systems. In private sector obtained data are used considerably more (approximately $80 \%$ ) than in public organizations (approximately 50\%) (Leković et al., 2015, pp. 28-29). Research conducted in hotels in Serbia shows that periodical performance evaluation is being conducted in $71 \%$ of hotels, while $64 \%$ of employees are familiar with the reasons, goals and terms of evaluation process. According to the estimation of respondents, the greatest importance of evaluation reflects in feedback on the accomplished task (average rank 2.15), in determining appropriate employee wages (average rank 2.46) and as the basis for promotion or demotion of employees (average rank 2.50). It is interesting that the performance evaluation is not seen as an important instrument for the evaluation of trainings attended by employees (average rank 6.00).
Cranet research shows that the average employee fluctuation in Serbia, according to the analyzed companies, is $6.59 \%$. In private sector, fluctuation is $7.68 \%$, while in public sector it amounts to $4.48 \%$. Employee fluctuation rate is above acceptable in all of the surveyed organizations (over 5\%) (Leković et al., 2015, p. 9). 57\% of analyzed fluctuations are between 6 and $10 \%$ while it amounts to $16-20 \%$ in 22 cases. Those data clearly show that the fluctuation rate in the hotel industry is higher than average and that there is a need to carefully analyze and eliminate the reasons of such high fluctuation rate. Half of the respondents do not perform exit interviews, which additionally disables the detection and elimination of causes.

The most common reasons for leaving the organization are: new job or self-employment (average rank 1.85), the expiry of contract (average rank 2.79) and job dissatisfaction (average rank 2.86).

The development of employees' career presents a very important HRM activity. According to Cranet research, most of the companies do not use modern techniques for employee career development, such as development centers, fast promotion schemes or international working arrangements. More than $40 \%$ of respondents use mentorship and trainings.

In contrast to the rest of the economy, according to this research conducted among hotel companies, the majority of respondents are aware of the problem of employee fluctuation. $77 \%$ of them have created incentive programs, designed with the aim of keeping the employees. The most common method in this context is offering promotion possibilities.

\section{CONCLUSION}

Human resource management is a very significant segment of the hotel industry and its importance is constantly growing. Hotels have a very important task to attract, engage and retain top talents, through redefining of working environment, and creation of stimulating working environment. Effective HR managers have to keep pace with business practices and tendencies, which are constantly developing in order to increase the level of employee efficiency and effectiveness, with the aim of creating competitive advantages in the hotel market, which is getting more demanding each day. Cranet research, which was conducted in 2015 among 20 hotels, has showed that the HRM practice in Serbia is more than similar. Due to the importance of human resources 


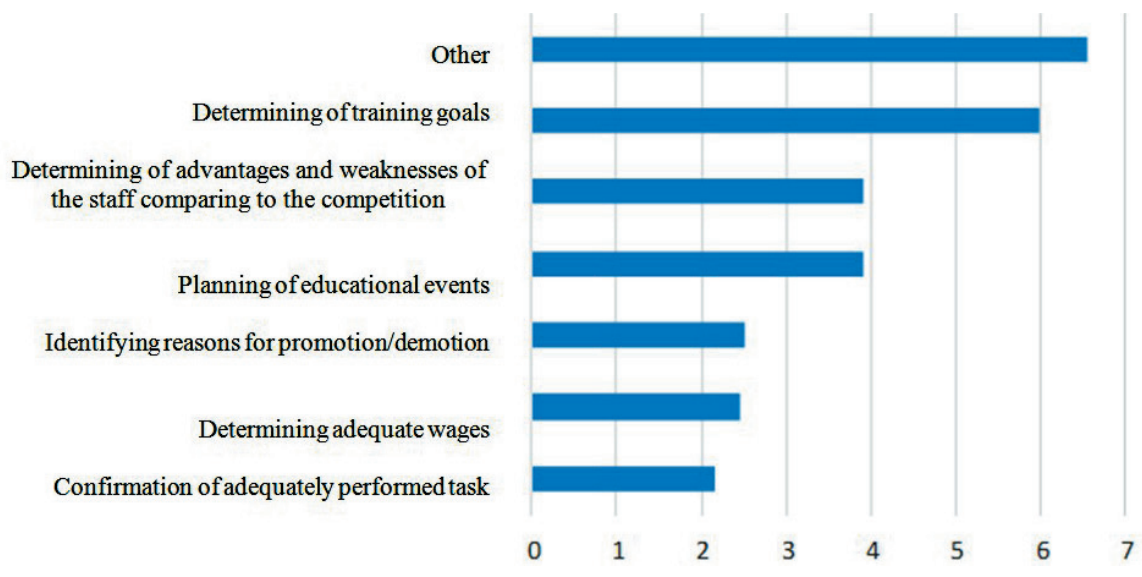

Figure 4. Estimation of evaluation importance

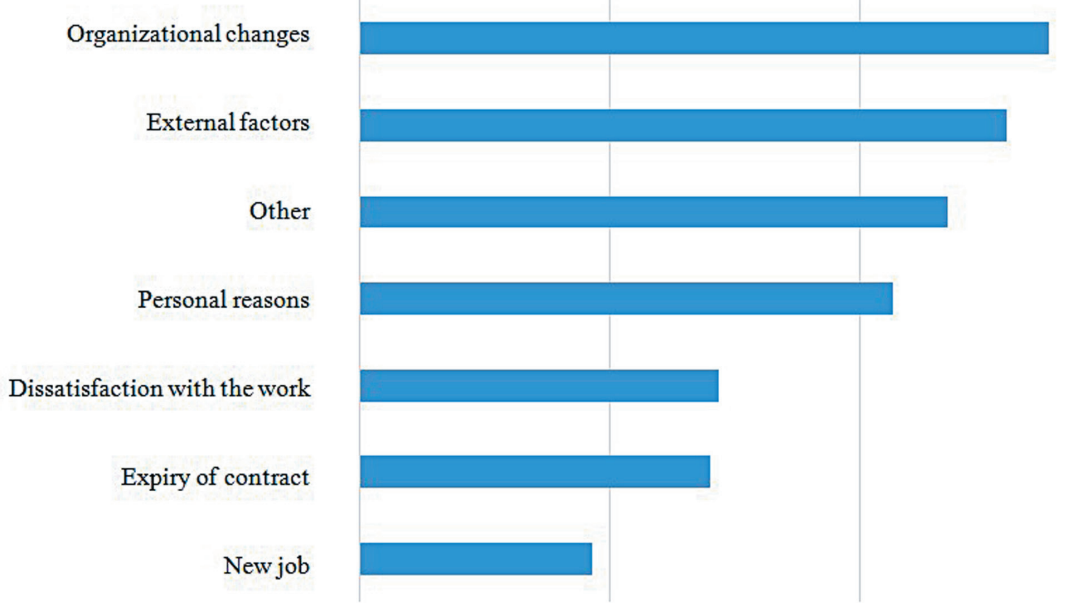

Figure 5. Evaluation of acquired knowledge

\begin{abstract}
Team spirit building
Socialising of employees

Assistance in problem solving

Close relations with employees

Higher salaries

Improvement possibilities

Safety of the working place

Promotion
\end{abstract}

Possibility of changing the job within the company

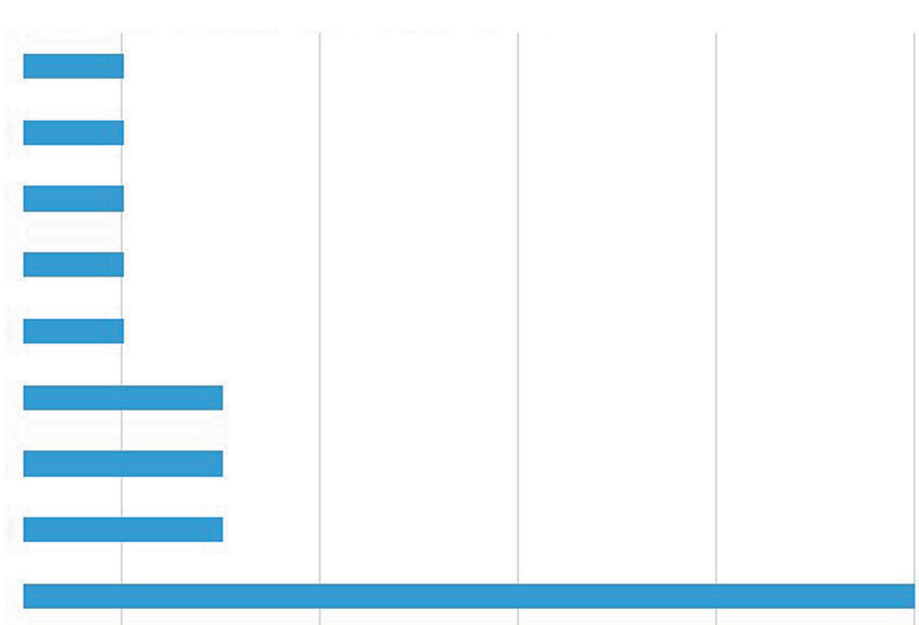

Figure 6. Incentive programs for keeping the employees 
in providing specific hotel service and increasing competition in the hotel market, hotel managers pay greater attention to trainings, development and incentive programs in order to retain human resources, compared to other economic activities in Serbia.

\section{REFERENCES}

Boardman, J., \& Barbato, C. (2008). Review of socially responsible HR practice and labor relations in international hotel chains. Retrived August 1, 2016 from http://www.ilo.org/wcmsp5/groups/public/--ed_dialogue/---sector/documents/publication/ wcms_162286.pdf
Leković, B., Slavić, A., \& Berber, N. (2015). Praksa upravljanja ljudskim resursima u Srbiji - 2014/2015: Izveštaj Cranet istraživanja. Retrived August 1, 2016 from http://www.ef.uns.ac.rs/cranet/download/Cranet_2015_Srbija_izvestaj.pdf

Shangri-La. (2014). Case 24 Shangri-La Hotels. Retrived August 1, 2016 from http://documents.mx/documents/shangri-la-558447708773f.html

WTTC. (2015). Global Talent Trends and Issues for the Travel and Tourism Sector. Retrived August 1, 2016 from http://www.wttc.org/-/media/382bb1e90c374 262bc951226a6618201.ashx 